\title{
R0 resection following chemo (radio)therapy improves survival of primary inoperable pancreatic cancer patients. Interim results of the German randomized CONKO-007 \pm trial
}

\author{
R. Fietkau ${ }^{1}$ - R. Grützmann² - U. A. Wittel ${ }^{3} \cdot$ R. S. Croner ${ }^{4}$ L. Jacobasch ${ }^{5}$ U. U. P. Neumann ${ }^{6}$ A. Reinacher-Schick . $^{7}$ \\ D. Imhoff ${ }^{8}$ S. Boeck ${ }^{9}$ L. Keilholz ${ }^{10} \cdot$ H. Oettle ${ }^{11} \cdot$ W. M. Hohenberger ${ }^{2} \cdot$ H. Golcher ${ }^{2}$ W. O. Bechstein ${ }^{12} \cdot$ W. Uhl $^{13}$.

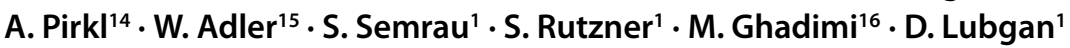

Received: 18 June 2020 / Accepted: 11 August 2020 / Published online: 10 September 2020

(c) The Author(s) 2020

\begin{abstract}
Purpose Chemotherapy with or without radiotherapy is the standard in patients with initially nonmetastatic unresectable pancreatic cancer. Additional surgery is in discussion. The CONKO-007 multicenter randomized trial examines the value of radiotherapy. Our interim analysis showed a significant effect of surgery, which may be relevant to clinical practice. Methods One hundred eighty patients received induction chemotherapy (gemcitabine or FOLFIRINOX). Patients without tumor progression were randomized to either chemotherapy alone or to concurrent chemoradiotherapy. At the end of therapy, a panel of five independent pancreatic surgeons judged the resectability of the tumor.
\end{abstract}

R. Fietkau and R. Grützmann contributed equally to this work as first author.

M. Ghadimi and D. Lubgan contributed equally to this work as last author.

Availability of data and material: \pm CONKO-007, official title: Chemoradiation following induction chemotherapy in locally advanced, unresectable pancreatic cancer-a randomised phase 3 trial: chemoradiation following induction chemotherapy compared with chemotherapy alone (EudraCT: 2009-014476-21, NCT01827553)

Code availability: Not applicable

$\triangle$ Prof. Dr. R. Fietkau

rainer.fietkau@uk-erlangen.de

1 Department of Radiation Oncology,

Friedrich-Alexander-Universität Erlangen-Nürnberg (FAU), Erlangen, Germany

2 Department of Surgery, Friedrich-Alexander-Universität Erlangen-Nürnberg (FAU), Erlangen, Germany

3 Department for General- and Visceral Surgery, Medical Center and Faculty of Medicine, University of Freiburg, Freiburg, Germany

4 Department of Surgery, University Hospital Magdeburg, Magdeburg, Germany

5 Private practice, Hematology/Oncology, Dresden, Germany

6 Department of Surgery, University Hospital RWTH Aachen, Aachen, Germany
7 Department for Hematology, Oncology and Palliative Care, St Josef-Hospital, Ruhr-University Bochum, Bochum, Germany

8 Department of Radiation Oncology, Universitätsklinikum Frankfurt, Frankfurt, Germany

9 Department of Medical Oncology and Comprehensive Cancer Centre, Klinikum Grosshadern,

Ludwig-Maximilians-University of Munich, Munich, Germany

10 Department of Radiotherapy, Clinical Center Bayreuth, Bayreuth, Germany

11 Outpatient Department Hematology/Oncology, Friedrichshafen, Germany

12 Department of General and Visceral Surgery, Frankfurt University Hospital and Clinics, Frankfurt, Germany

13 Department of Surgery, St. Josef Hospital, Ruhr-University Bochum, Bochum, Germany

14 Medical Centre for Information and Communication Technology, Friedrich-Alexander-Universität Erlangen-Nürnberg (FAU), Erlangen, Germany

15 Department of Medical Informatics, Biometry and Epidemiology, University of Erlangen-Nürnberg, Waldstraße 6, 91054 Erlangen, Germany

16 Department of General, Visceral and Pediatric Surgery, Medical Center, Georg-August-University Göttingen, Göttingen, Germany 
Results Following induction chemotherapy, 126/180 patients $(70.0 \%)$ were randomized to further treatment. Following study treatment, 36/126 patients (28.5\%) underwent surgery; (R0: 25/126 [19.8\%]; R1/R2/Rx [n=11/126; 6.1\%]). Disease-free survival (DFS) and overall survival (OS) were significantly better for patients with R0 resected tumors (median DFS and OS: 16.6 months and 26.5 months, respectively) than for nonoperated patients (median DFS and OS: 11.9 months and 16.5 months, respectively; $p=0.003)$. In the 25 patients with R0 resected tumors before treatment, only $6 / 113(5.3 \%)$ of the recommendations of the panel surgeons recommended R0 resectability, compared with $17 / 48(35.4 \%)$ after treatment $(p<0.001)$.

Conclusion Tumor resectability of pancreatic cancer staged as unresectable at primary diagnosis should be reassessed after neoadjuvant treatment. The patient should undergo surgery if a resectability is reached, as this significantly improves their prognosis.

Keywords Pancreatic adenocarcinoma $\cdot$ Surgery $\cdot$ Tumor resectability $\cdot$ Neoadjuvant chemoradiotherapy $\cdot$ Prospective randomized multicenter trial

\section{Introduction}

Pancreatic cancer is currently the fourth leading cause of cancer-related death worldwide [1]. Palliative chemotherapy remains the only treatment option for the $50 \%$ of patients with distant metastases at first diagnosis. According to the National Comprehensive Cancer Network (NCCN) guidelines, pancreatic cancer without distant metastasis is divided into three categories: resectable, borderline resectable, and locally advanced unresectable. Primary surgery is recommended for the $10 \%-15 \%$ of patients who initially have curatively resectable tumors [2]. Patients with borderline resectable pancreatic cancer should receive neoadjuvant treatment followed by surgery, and those with locally advanced unresectable pancreatic cancer should receive palliative treatment [3]. It remains unclear whether patients with initially unresectable pancreatic cancer can achieve resectable status and, if so, whether surgery provides them any additional benefit [4-6]. There are only some case series and small phase II trials supporting surgery in primarily inoperable patients. However, findings from larger prospective studies investigating tumor resectability both before and after treatment are still lacking [7].

The CONKO-007 study was designed to examine the value of radiotherapy in patients with nonmetastatic, unresectable pancreatic cancer [6, 8, 9]; radiotherapy has also been tested in other tumor entities [10, 11]. The protocol stipulates that the resectability of each patient shall be assessed by a panel of five experienced pancreatic surgeons before inclusion in the study to exclude patients with initially resectable pancreatic cancer. Following the neoadjuvant study treatment, the panel surgeons again assess the tumor resectability. The panel surgeons' recommendations were not binding for the local surgeons, but it was recommended to explore patients with resectable cancer.

Based on the results of a planned interim analysis performed after 180 patients were recruited, independent experts recommended continuation of the study for further ex- amination of the primary outcome (overall survival). Analysis of the secondary outcomes showed that patients who achieved R0 resection following the study treatment had a better prognosis than nonoperated patients. The study steering committee decided to publish these findings because these results may influence the fundamental treatment paradigm for unresectable locally advanced pancreatic cancer. Because these data do not affect the primary outcome of the trial, we consider their publication to be noncritical.

\section{Material and methods}

\section{Study design and patients}

CONKO-007 is an open-label, multicenter, phase III randomized clinical trial to examine the effectiveness of chemoradiotherapy compared with chemotherapy alone after induction chemotherapy with gemcitabine or FOLFIRINOX (physician's decision; no randomization) in patients with nonmetastatic, initially locally advanced unresectable pancreatic cancer (Fig. 1).

Eligibility criteria for the trial are age $\geq 18$ years; histologically confirmed, unresectable adenocarcinoma of the pancreas; no evidence of distant metastasis as determined by computed tomography (CT) of the thorax and abdomen; and ECOG performance status $\leq 2$. Patients had to give their written informed consent before participating in the study. The trial was conducted according to ICH GCP guidelines and was approved by the central ethics committee of the University Hospital of Erlangen, Germany (approval no. 322_12AZ) and by the Federal Institute for Drugs and Medical Devices (BfArM, 4038763). Trial registration (EudraCT: 2009-014476-21, NCT01827553) was obtained prior to recruitment.

From 2013 to December 2015, 180 patients were recruited from 52 centers in Germany, more than six patients were enrolled from each of the centers in the following 


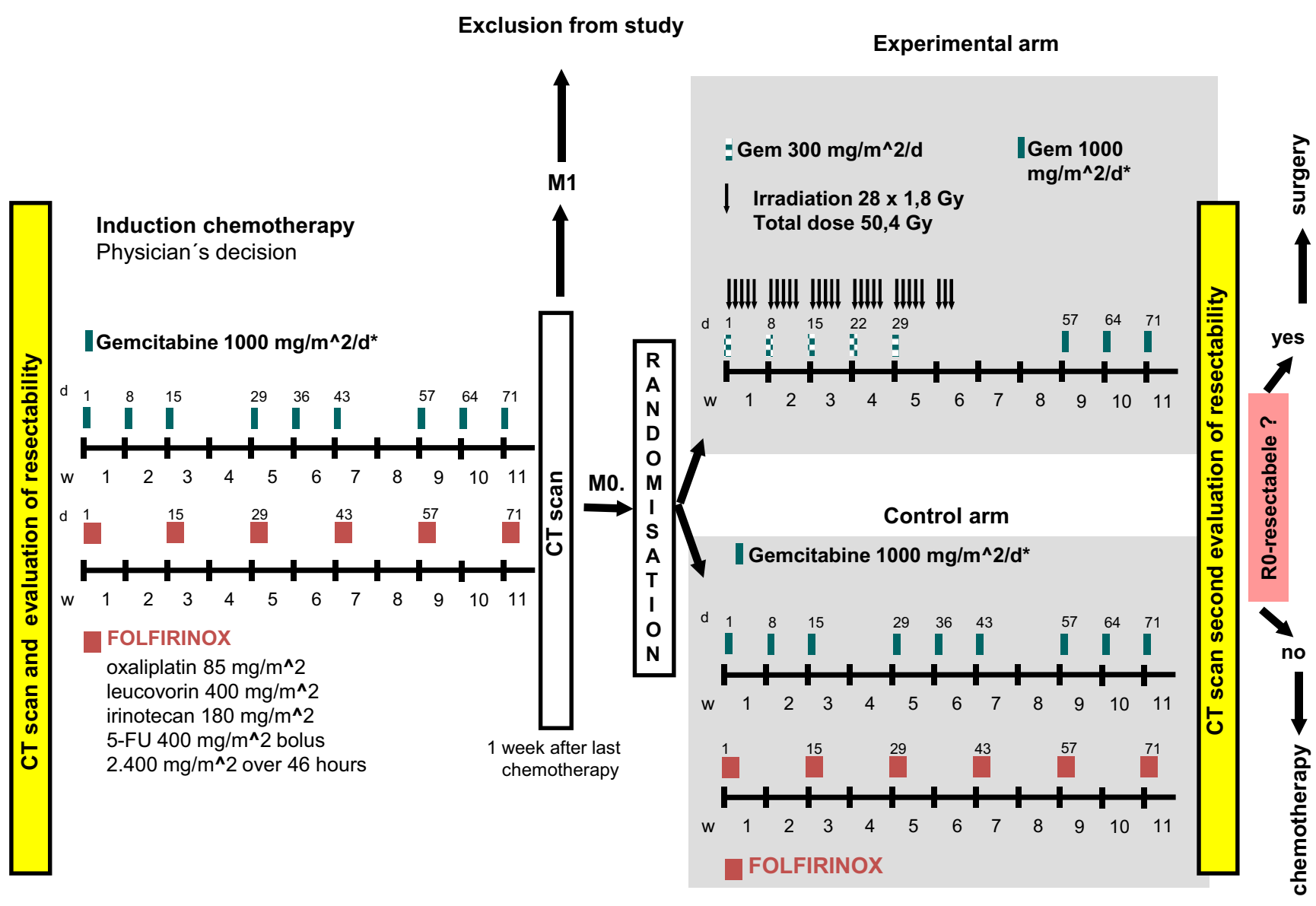

Fig. 1 Trial schedule including study inclusion, evaluation for resectability, induction chemotherapy, randomization, therapy after randomization, and subsequent evaluation of resectability at the end of the trial

cities: Erlangen, Magdeburg, Göttingen, Freiburg, Dresden, Aachen, Bochum, Frankfurt, Munich, Bayreuth.

After inclusion, each patient's anonymized diagnostic images ( $\mathrm{CT}$ or, in exceptional cases, magnetic resonance imaging $[\mathrm{MRI}]$ ) using a GCP-certified, commercially available clinical trials management system (SecuTrial, interActive Systems, Berlin, Germany [14]) were submitted to five surgeons or an interdisciplinary tumor board, who assessed the resectability status as either "unresectable," "complete R0 resection possible," or "R0 resection undetermined" with the aid of a standard questionnaire (Wittel et al., under revision, BMC Cancer). The assessment procedure was repeated 4 weeks after the patients completed the study treatment. The panel results were submitted to the centers within 3 work days but were nonbinding. However, the protocol recommendation was to perform surgery in those cases determined to be resectable. Unresectable patients were given the option to continue treatment with chemotherapy outside of the trial.

Induction chemotherapy consisted of either gemcitabine or FOLFIRINOX, depending on the patient's general health (as determined by the responsible treatment center). Restag- ing was performed following 6 cycles of FOLFIRINOX or $3 \times 3$ infusion of gemcitabine. Patients with new distant metastases or those who had received less than twothirds of the planned chemotherapy were excluded from the study. The remaining patients were randomized to receive either chemotherapy alone with the existing regimen (FOLFIRINOX or gemcitabine) or concurrent chemoradiotherapy with gemcitabine.

Randomization was done with computer-generated block-randomization codes stratified by center, gender, and type of induction chemotherapy (gemcitabine or FOLFIRINOX).

\section{Chemotherapy (physician's decision; no randomization)}

Gemcitabine $1000 \mathrm{mg} / \mathrm{m}^{2}$ was delivered by a 30 -min intravenous infusion on days 1,8 , and 15 , followed by a repeat cycle on day 29 (days 29, 36, and 43) and day 57 (days 57, 64, and 71). During radiotherapy, patients received gemcitabine $300 \mathrm{mg} / \mathrm{m}^{2}$ by a $30-\mathrm{min}$ intravenous infusion on days $1,8,15,22$, and 29 . 
FOLFIRINOX [12] consisted of a 2-h intravenous infusion of oxaliplatin $85 \mathrm{mg} / \mathrm{m}^{2}$ followed by a 2 -h intravenous infusion of leucovorin $400 \mathrm{mg} / \mathrm{m}^{2}$ and, after a 30-min break, a 90 -min intravenous infusion of irinotecan $180 \mathrm{mg} / \mathrm{m}^{2}$. Subsequently, patients received an intravenous bolus infusion of 5 -fluorouracil $400 \mathrm{mg} / \mathrm{m}^{2}$ followed by a continuous intravenous infusion of 5-fluorouracil $2400 \mathrm{mg} / \mathrm{m}^{2}$ over $46 \mathrm{~h}$. This cycle was repeated in weeks $3,5,7,9$, and 11 (days 15, 29, 43, 57, and 71).

\section{Radiotherapy}

Radiotherapy (intensity-modulated radiation therapy [IMRT] or three-dimensional [3D] radiotherapy techniques) consisted of a total dose of $50.4 \mathrm{~Gy}$ in 28 fractions (1.8 Gy/day delivered at a minimum energy of $6 \mathrm{MV})$. Following induction chemotherapy, the target volume included the primary tumor and suspected lymph nodes with a safety margin of $1 \mathrm{~cm}$. Respiratory motion of the tumor was taken into account in radiation delivery.

\section{Statistical analysis}

Disease-free survival (DFS) was measured from the date of informed consent until one of the following events occurred: distant metastases, local relapse, progress, or death from any cause. For overall survival (OS), death by any cause was defined as event. Patients without any event were censored at the date of their last follow-up. Survival was estimated by Kaplan-Meier analysis. Survival differences were examined with the log-rank test. Differences of R0 resectability before and after treatment, as judged by at least three surgeons per patient, were examined via generalized estimating equations (GEE models). Here, the surgeon's assessment was used as the independent variable, and the time point (before versus after treatment) was used as the dependent variable. The GEE models account for correlations between assessments of surgeons for the same patients and correlations between patients at different time points. Differences in patient characteristics were examined using Fisher's exact test and the Kruskal-Wallis test. All tests were two-sided, and the level of significance was set at $p<0.05$. All statistical analysis was performed using $\mathrm{R}$ version 3.4.1[13].

\section{Results}

\section{Feasibility of induction chemotherapy}

Induction chemotherapy consisted of gemcitabine in 43 cases and FOLFIRINOX in 137 cases. Compliance was excellent in both groups: $42 / 43$ patients in the gemcitabine group received a median of $94.8 \%$ (mean $86.8 \pm 19.5$, range 0.0-111.8) of the planned chemotherapy dose, and one patient withdrew before the start of induction chemotherapy. The patients in the FOLFIRIONOX group received a median of $87.0 \%$ (mean $80.8 \pm 23.6$, range $16.4-120.9$ ) of

Fig. 2 CONSORT diagram

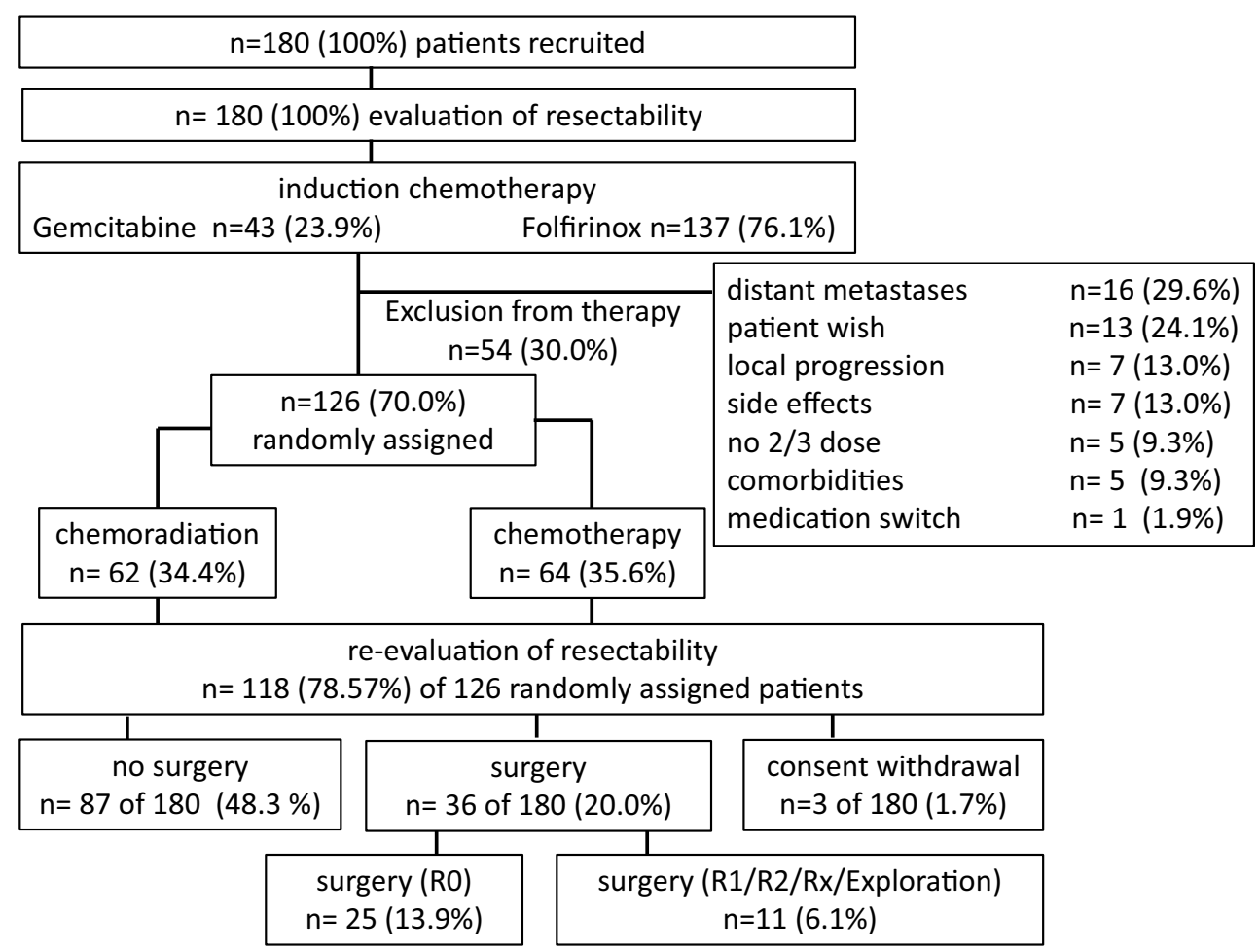


Table 1 Patient characteristics

\begin{tabular}{|c|c|c|c|c|c|c|c|c|c|}
\hline & $\begin{array}{l}\text { All } \\
\text { patients }\end{array}$ & $\%$ & R0 & $\%$ & $\mathrm{R} 1 / \mathrm{R} 2 / \mathrm{Rx}$ & $\%$ & $\begin{array}{l}\text { No } \\
\text { surge }\end{array}$ & $\%$ & $p$ value \\
\hline Number of patients & 180 & 100 & 25 & 13.9 & 11 & 6.1 & 144 & 80 & N/A \\
\hline Age at start of study & $\begin{array}{l}66 \\
(41-79)\end{array}$ & N/A & $\begin{array}{l}63 \\
(45-73)\end{array}$ & N/A & $\begin{array}{l}70 \\
(44-79)\end{array}$ & N/A & $\begin{array}{l}66.5 \\
(41-\end{array}$ & N/A & $\begin{array}{l}0.205 \\
(\mathrm{~K}-\mathrm{W})\end{array}$ \\
\hline \multicolumn{10}{|l|}{ ECOG at start of study } \\
\hline ECOG 0 & 87 & 48.3 & 14 & 56.0 & 6 & 54.5 & 67 & 46.5 & \multirow{4}{*}{$\begin{array}{l}0.867 \\
(\mathrm{~F})\end{array}$} \\
\hline ECOG 1 & 78 & 43.3 & 10 & 40.0 & 4 & 36.4 & 64 & 44.5 & \\
\hline ECOG 2 & 14 & 7.8 & 1 & 4.0 & 1 & 9.1 & 12 & 8.3 & \\
\hline ECOG missing in the database & 1 & 0.6 & 0 & 0 & 0 & 0 & 1 & 0.7 & \\
\hline \multicolumn{10}{|l|}{ Sex } \\
\hline Male & 114 & 63.3 & 17 & 68.0 & 7 & 63.6 & 90 & 62.5 & \multirow{2}{*}{$\begin{array}{l}0.909 \\
(\mathrm{~F})\end{array}$} \\
\hline Female & 66 & 36.7 & 8 & 32.0 & 4 & 36.4 & 54 & 37.5 & \\
\hline \multicolumn{10}{|l|}{ Tumor stage } \\
\hline $\mathrm{cT} 1 / \mathrm{cT} 2$ & 9 & 5 & 1 & 4.0 & 1 & 9.1 & 7 & 4.9 & \multirow{4}{*}{$\begin{array}{l}0.415 \\
(\mathrm{~F})\end{array}$} \\
\hline $\mathrm{cT} 3 / \mathrm{cT} 4$ & 134 & 74.4 & 21 & 84.0 & 10 & 90.9 & 103 & 71.5 & \\
\hline Not available & 36 & 20 & 3 & 12.0 & 0 & 0 & 33 & 22.9 & \\
\hline cT missing in the database & 1 & 0.6 & 0 & 0.0 & 0 & 0 & 1 & 0.7 & \\
\hline \multicolumn{10}{|l|}{ Nodal status: } \\
\hline $\mathrm{cNO}$ & 50 & 27.8 & 7 & 28.0 & 5 & 45.4 & 38 & 26.4 & \multirow{4}{*}{$\begin{array}{l}0.412 \\
(\mathrm{~F})\end{array}$} \\
\hline $\mathrm{cN}+$ & 70 & 38.9 & 11 & 44.0 & 4 & 36.4 & 55 & 38.2 & \\
\hline Not available & 59 & 32.7 & 7 & 28.0 & 2 & 18.2 & 50 & 34.7 & \\
\hline $\mathrm{cN}$ missing in the database & 1 & 0.6 & 0 & 0.0 & 0 & 0 & 1 & 0.7 & \\
\hline \multicolumn{10}{|l|}{ Tumor grading: } \\
\hline G1 & 2 & 1.1 & 0 & 0.0 & 0 & 0 & 2 & 1.4 & \multirow{5}{*}{$\begin{array}{l}0.875 \\
(\mathrm{~F})\end{array}$} \\
\hline $\mathrm{G} 2$ & 69 & 38.3 & 11 & 44.0 & 2 & 18.2 & 56 & 38.9 & \\
\hline G3 & 50 & 27.8 & 6 & 24.0 & 4 & 36.4 & 40 & 27.8 & \\
\hline Not available & 57 & 31.7 & 7 & 28.0 & 5 & 45.4 & 45 & 31.2 & \\
\hline $\mathrm{G}$ missing in the database & 2 & 1.1 & 1 & 4.0 & 0 & 0 & 1 & 0.7 & \\
\hline \multicolumn{10}{|l|}{ Type of surgery: } \\
\hline $\begin{array}{l}\text { Pancreatoduodenectomy } \\
\text { (Whipple technique) }\end{array}$ & 13 & 7.2 & 13 & 52.0 & 0 & 0 & - & - & \multirow[t]{8}{*}{$\begin{array}{l}<0.001 \\
\text { (F) }\end{array}$} \\
\hline Distal pancreatectomy & 7 & 3.9 & 5 & 20.0 & 2 & 18.2 & - & - & \\
\hline Total pancreatectomy & 6 & 3.3 & 5 & 20.0 & 1 & 9.1 & - & - & \\
\hline Core biopsy & 0 & 0 & 0 & 0.0 & 0 & 0 & - & - & \\
\hline $\begin{array}{l}\text { No resection } \\
\text { Surgical exploration only }\end{array}$ & 7 & 3.9 & 0 & 0.0 & 7 & 63.6 & - & - & \\
\hline Type of surgery unknown & 3 & 1.7 & 2 & 8.0 & 1 & 9.1 & - & - & \\
\hline No surgery & 141 & 78.3 & 0 & 0.0 & - & - & - & - & \\
\hline $\begin{array}{l}\text { Consent withdrawn prior to } \\
\text { evaluation of resectability at } \\
\text { end of study }\end{array}$ & 3 & 1.7 & - & - & - & - & - & - & \\
\hline $\begin{array}{l}\text { CA19-9 prior therapy }(\mathrm{U} / \mathrm{ml}) \\
\text { median (range) }\end{array}$ & \multicolumn{2}{|c|}{$\begin{array}{l}347.2 \\
(0.60-26,081.00)\end{array}$} & \multicolumn{2}{|c|}{$\begin{array}{l}278.9 \\
(0.60-4613.56)\end{array}$} & \multicolumn{2}{|c|}{$\begin{array}{l}232.0 \\
(2.0-4743.11)\end{array}$} & \multicolumn{2}{|c|}{$\begin{array}{l}421.5 \\
(0.70-26,081.0)\end{array}$} & $\begin{array}{l}0.43 \\
(\mathrm{~K}-\mathrm{W})\end{array}$ \\
\hline $\begin{array}{l}\text { CEA prior therapy }(\mathrm{ng} / \mathrm{ml}) \\
\text { median (range) }\end{array}$ & \multicolumn{2}{|c|}{$\begin{array}{l}3.45 \\
(0.50-680.00)\end{array}$} & \multicolumn{2}{|c|}{$\begin{array}{l}2.9 \\
(0.90-111.10)\end{array}$} & \multicolumn{2}{|c|}{$\begin{array}{l}2.90 \\
(0.90-104.0)\end{array}$} & \multicolumn{2}{|c|}{$\begin{array}{l}3.6 \\
(0.50-680.0)\end{array}$} & $\begin{array}{l}0.216 \\
(\mathrm{~K}-\mathrm{W})\end{array}$ \\
\hline
\end{tabular}

Data are shown as the median and (range) unless indicated otherwise $N / A$ not applicable, $K$ - $W$ Kruskal-Wallis test, $F$ Fisher's exact test 
the planned oxaliplatin dose, $87.0 \%$ (mean $80.4 \pm 24.3$, range $8.3-120.9$ ) of the irinotecan dose, and $89.0 \%$ (mean $82.2 \pm 23.9$, range 16.4-120.9) of the leucovorin dose, followed by a median of $85.3 \%$ (mean $74.5 \pm 30.9$, range $0.0-120.9$ ) of the 5-fluorouracil $400 \mathrm{mg} / \mathrm{m}^{2}$ dose delivered by intravenous bolus infusion and $90.6 \%$ (mean $82.2 \pm 23.8$, range $16.4-120.9$ ) of the 5-fluorouracil $2400 \mathrm{mg} / \mathrm{m}^{2}$ dose administered by a continuous intravenous infusion over $46 \mathrm{~h}$.

\section{Randomization}

Following induction chemotherapy, 126/180 patients (70.0\%) were randomized to further treatment and 54 patients were not (Fig. 2). The main reasons for nonrandomization were distant metastases $(29.6 \%)$, patient request (24.1\%), local progression (13.0\%), side effects $(13.0 \%)$, insufficient dose of induction chemotherapy (9.3\%), concomitant disease $(9.3 \%)$, and treatment switch $(1.9 \%)$.

\section{Surgery after completion of study treatment}

Following study treatment, 36/180 patients $(20.0 \%)$ underwent surgery and $87 / 180(48.3 \%)$ received no surgery. R0 resection was achieved in 25 cases $(19.8 \%$ of the randomized 126 patients and $13.9 \%$ of the overall group of 180 study patients) versus exploration $(n=7)$ or $\mathrm{R} 1 / \mathrm{R} 2 / \mathrm{Rx}$ $(n=4)$ resection in 11 cases $(6.1 \%)$. Patients with $\mathrm{R} 1 / \mathrm{R} 2$ resection and explorative surgery were put together because of the low number of patients. Nevertheless, a more detailed analysis-i.e., R1 resection versus $\mathrm{R} 2$ resection-must be done in the final analysis, and no conclusions should be drawn from this up to now. The baseline characteristics were well balanced (Table 1).

\section{Postoperative complications}

Five of $36(13.8 \%)$ surgically treated patients developed postoperative complications of grade 3 or worse: bleeding $(n=1)$, pancreatic fistula $(n=1)$, wound healing disturbance $(n=1)$, ileus $(n=1)$, and insufficiency of anastomosis $(n=1)$. Two of $36(5.5 \%)$ patients died from complications: one died on the day after surgery (acute liver failure), and the other died 36 days after surgery (multiple organ failure with sepsis).

\section{Survival rate as a function of surgical treatment}

Disease-free survival (DFS) was 11.2 months in the overall population $(n=180)$ compared to 16.6 months in the R0 $(n=25)$ resection group. The prognosis of patients with $\mathrm{R} 0$ resection was significantly better $(p=0.003)$ than that of nonoperated patients (DFS 11.9 months) or patients

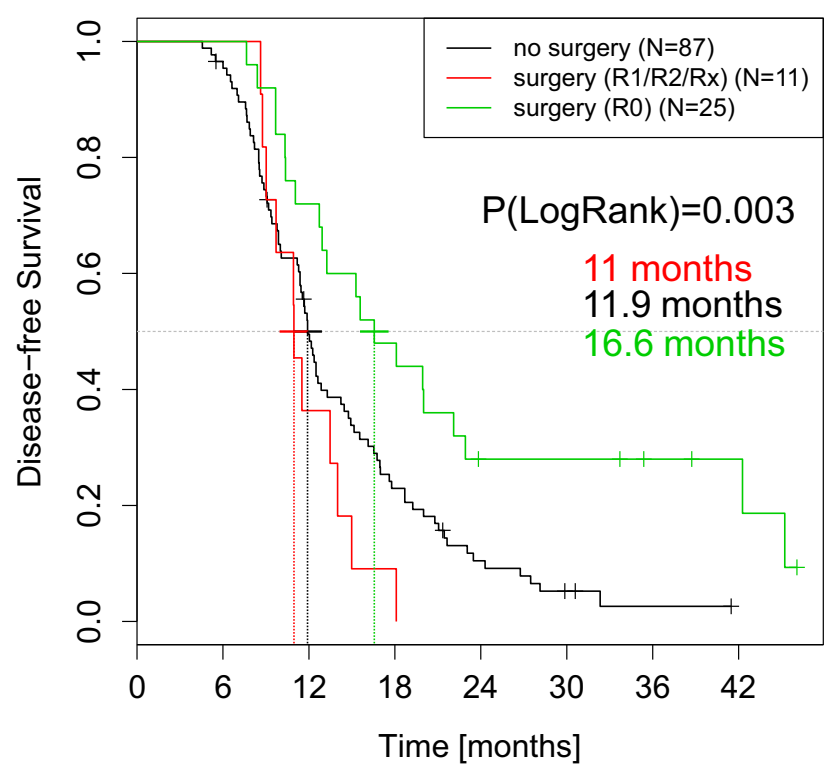

Number at risk:

$\begin{array}{lcccccccc}\text { no surgery } & 87 & 83 & 41 & 19 & 8 & 3 & 1 & 0 \\ \text { surgery } & 11 & 11 & 4 & 1 & 0 & 0 & 0 & 0 \\ (\mathrm{R} 1 / \mathrm{R} 2 / \mathrm{Rx}) & 11 & 25 & 18 & 12 & 6 & 6 & 4 & 3 \\ \text { surgery (R0) } & 25 & 25\end{array}$

Fig. 3 Disease-free survival rates of randomized patients $(n=126)$ : R0-resected patients (green curve) in relation to R1/R2/Rx-resected patients (red curve) and patients without surgery (black curve). Median survival rates are given in months

in the exploration or $\mathrm{R} 1 / \mathrm{R} 2 / \mathrm{Rx}$ resection group (DFS 11.0 months; Fig. 3). At the 24-month follow-up, the median tumor-free survival rate was $28.0 \%(95.0 \% \mathrm{Cl}$ : 14.9-52.5) in the $\mathrm{R} 0$ resection group, $10.0 \%(95.0 \% \mathrm{Cl}$ : 8.6-0.20.9) in the nonoperated group, and $0.0 \%$ in the exploration or $\mathrm{R} 1 / \mathrm{R} 2 / \mathrm{Rx}$ resection group ( $p=0.003)$.

These data also carry over to the overall survival (OS) rate. Median OS was 15.0 months in the overall population $(n=180)$ compared to 26.5 months in the $\mathrm{R} 0$ resection group ( $n=25)$. Patients with R0-resected tumors had significantly better median OS (26.5 months, $n=25)$ than nonoperated patients ( 16.5 months, $n=87)$ and patients in the exploration or R1/R2/Rx resection group (16.9 months, $n=11$; Fig. 4). Two-year survival was $72.0 \%$ (95\% CI: 56.4-91.9) in the R0 resection group compared to $30.0 \%(95.0 \% \mathrm{CI}$ : $21.4-41.9)$ in the nonoperated group and $27 \%(95.0 \% \mathrm{Cl}$ : $10.4-71.6, p=0.003$ ) in the exploration or $\mathrm{R} 1 / \mathrm{R} 2 / \mathrm{Rx}$ resection group.

\section{R0 resectability assessments before and after neoadjuvant treatment}

All 25 patients with R0 resected tumors were assessed for tumor resectability by at least three surgeons before treatment, and 24/25 were assessed after completing the study. 


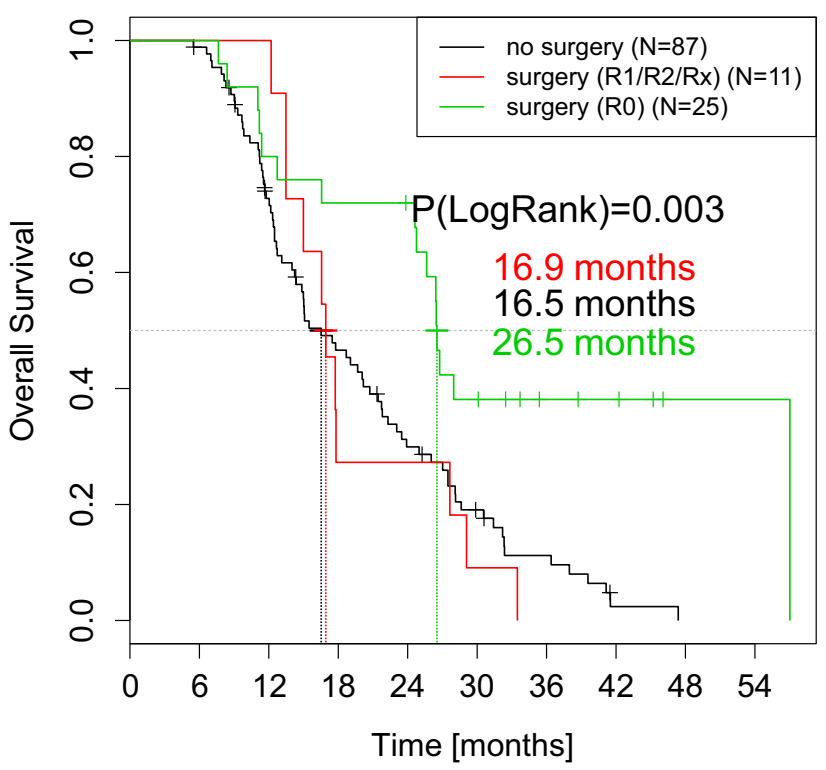

Number at risk:

$\begin{array}{lcccccccccc}\text { no surgery } & 87 & 85 & 59 & 37 & 23 & 13 & 7 & 1 & 0 & 0 \\ \text { surgery } & 11 & 11 & 11 & 3 & 3 & 1 & 0 & 0 & 0 & 0 \\ \text { (R1/R2/Rx) } & 11 & 25 & 20 & 18 & 17 & 9 & 5 & 4 & 1 & 1\end{array}$

Fig. 4 Overall survival rates of randomized patients $(n=126)$ : R0-resected patients (green curve) in relation to R1/R2/Rx-resected patients (red curve) and patients without surgery (black curve). Median survival rates are given in months

The results of the resectability assessments performed before and after treatment differed significantly, as determined using the GEE model. Each surgeon could submit one resectability decision per case (113 pretreatment resectability decisions for 25 patients and 58 posttreatment resectability decisions for 24 patients). The number of R0 resectable decisions rose from $5.3 \%(6 / 113)$ before treatment to $29.3 \%$ (17/58) after treatment $(p<0.001$, as determined according to the GEE model; Table 2).

The proportion of borderline resectable (=R0 questionable) decisions increased from $24.8 \%$ (28/113 decisions) before treatment to $46.6 \%$ (27/58 decisions) after treatment $(p=0.032)$.

In $23 / 25$ patients, at least one surgeon classified the case as unresectable before treatment compared to only 9/24 cases after treatment ("R0 resection not possible"). Accordingly, the number of "R0 resection not possible" decisions fell from $79 / 113(69.9 \%)$ before treatment to $14 / 58$ $(24.1 \%)$ after treatment $(p<0.001)$.

Taken together, these findings show that the pretreatment assessment result was "R0 resection not possible" or "borderline resectable" in the overwhelming majority of cases, but after the study treatment, only 12/24 patients were classified as unresectable or borderline resectable by all sur-
Table 2 Surgical assessment in the R0 resection group before $(n=25 \mathrm{pa}-$ tients) and after ( $n=24$ patients) the neoadjuvant therapy: tumor resectability was assessed by at least three surgeons. Each surgeon could submit one resectability decision per case

\begin{tabular}{lllllll}
\hline R0 & R0 & R0 & No. & R0 pos- & R0 ques- & R0 im- \\
pos- & ques- & im- & of & sible & tionable & possible \\
sible & $\begin{array}{l}\text { tion- } \\
\text { able }\end{array}$ & $\begin{array}{l}\text { pos- } \\
\text { sible }\end{array}$ & cases & $\begin{array}{l}\mathrm{x} \\
\text { no. of } \\
\text { cases }\end{array}$ & $\begin{array}{l}\text { no. of } \\
\text { cases }\end{array}$ & $\begin{array}{l}\text { no. of } \\
\text { cases }\end{array}$ \\
\hline
\end{tabular}

Before:

$\begin{array}{lllllll}2 & 3 & 0 & 1 & 2 & 3 & 0\end{array}$

$\begin{array}{lllllll}1 & 3 & 1 & 2 & 2 & 6 & 2\end{array}$

$\begin{array}{lllllll}1 & 2 & 2 & 1 & 1 & 2 & 2\end{array}$

$\begin{array}{lllllll}1 & 1 & 3 & 1 & 1 & 1 & 3\end{array}$

$\begin{array}{lllllll}0 & 3 & 0 & 1 & 0 & 3 & 0\end{array}$

$\begin{array}{lllllll}0 & 2 & 3 & 1 & 0 & 2 & 3\end{array}$

$\begin{array}{lllllll}0 & 2 & 2 & 3 & 0 & 6 & 6\end{array}$

$\begin{array}{lllllll}0 & 2 & 1 & 1 & 0 & 2 & 1\end{array}$

$\begin{array}{lllllll}0 & 1 & 4 & 1 & 0 & 1 & 4\end{array}$

$\begin{array}{lllllll}0 & 1 & 3 & 2 & 0 & 2 & 6\end{array}$

$\begin{array}{lllllll}0 & 0 & 5 & 8 & 0 & 0 & 40\end{array}$

$\begin{array}{lllllll}0 & 0 & 4 & 3 & 0 & 0 & 12\end{array}$

$n\left(\sum 113\right) \quad 6 \quad 6079$

After:

$\begin{array}{lllllll}3 & 1 & 0 & 1 & 3 & 1 & 0 \\ 3 & 0 & 0 & 1 & 3 & 0 & 0 \\ 2 & 1 & 0 & 2 & 4 & 2 & 0 \\ 2 & 0 & 0 & 1 & 2 & 0 & 0 \\ 1 & 2 & 0 & 1 & 1 & 2 & 0 \\ 1 & 1 & 1 & 2 & 2 & 2 & 2 \\ 1 & 1 & 0 & 1 & 1 & 1 & 0 \\ 1 & 0 & 0 & 1 & 1 & 0 & 0 \\ 0 & 3 & 0 & 1 & 0 & 3 & 0 \\ 0 & 2 & 1 & 1 & 0 & 2 & 1 \\ 0 & 2 & 0 & 5 & 0 & 10 & 0 \\ 0 & 1 & 1 & 3 & 0 & 3 & 3 \\ 0 & 1 & 0 & 1 & 0 & 1 & 0 \\ 0 & 0 & 3 & 2 & 0 & 0 & 6 \\ 0 & 0 & 2 & 1 & 0 & 0 & 2 \\ 0 & 0 & 0 & 1 & 0 & 0 & 0 \\ n \\ l\end{array}$

geons. In other words, neoadjuvant treatment led to a fundamental change in the surgeon's resectability assessment.

\section{Discussion}

Our interim analysis showed the significance of surgery for this type of cancer, which may be relevant to clinical practice. Therefore, the study steering committee decided to publish these interim results. However, the study is ongoing, so it is not possible to publish any conclusions regarding the primary outcome criteria at this time. 
CONKO-007 is one of the first trials in which the resectability of pancreatic cancer is assessed before and after study treatments by an independent panel of surgeons, based on pseudonymized diagnostic images. Only in the study of Katz et al. were the radiographic criteria centrally reviewed before therapy [14]. In other studies, resectability assessments were performed only by local surgeons, with the risk that personal experience, local peculiarities, or other selection factors could influence the assessment results. Moreover, resectability assessment criteria vary from one classification system to another, which leads to additional uncertainty. The use of pseudonymized diagnostic images and standardized questionnaires by our panel ensured maximum objectivity of the resectability assessments. The proportion of R0-resectable decisions prior to the neoadjuvant therapy in our study was only $5.3 \%$, and $69.9 \%$ confirmed that resection was surely not possible. This shows that the cohort truly consisted of patients with unresectable pancreatic cancer.

Ultimately, $20.0 \%$ of all study patients underwent surgery. R0 resection was achieved in $13.9 \%$ of all included patients and $19.8 \%(25 / 126)$ of all those who completed the study treatment. These percentages are lower than those published in the literature $[15,16]$. After FOLFIRINOX \pm chemoradiotherapy, Hosein et al., Nanda et al., Nitsche et al., Sadot et al., and Marthey et al. achieved R0 resection rates of $30.0 \%-44.0 \%$ [17-21]. Suker et al. in a meta-analysis found that the pooled proportion of patients with resection was $25.9 \%$; $\mathrm{R} 0$ resection was $78.4 \%$ based on the number of patients with surgery [22].

This variance in the proportions of patients with surgery and $\mathrm{R} 0$ resection can be attributed to differences in selection criteria between studies. In our trial, all patients were treated and observed prospectively. Consequently, this cohort should give a more realistic picture of the actual treatment reality. Moreover, because surgery was only a recommendation and not an obligation in this study, the rate might have been even higher if all centers had consistently followed the recommendation. However, this cannot be determined in retrospect. Thus, the resection rate achieved in this study should be regarded as a minimum value.

Median DFS and median OS for our patients with R0-resected tumors were 16.6 months and 26.5 months, respectively. These figures are in line with most of the published data in the literature, especially for pancreatic adenocarcinomas classified as unresectable. Median OS from the start of FOLFIRINOX ranged from 10.0 months to 32.7 months across studies by Hosein et al., Nanda et al., Nitsche et al., Sadot et al., and Marthey et al., with a pooled patient-level median OS of 24.2 months $(95.0 \%$ CI: 21.6-26.8 months) [17-21]. Moreover, 1-year OS was $80.0 \%$ (95.0\% CI: 74.7-84.4), and 2-year OS was 50.2\% (95.0\% CI: 42.9-57.5) [22].
Immediate surgery plus adjuvant gemcitabine alone [23, 24] or in combination with capecitabine [23] resulted in comparable median OS times of 24.5-25.5 months and 28 months, respectively.

The treatment results achieved in borderline-resectable pancreatic cancer patient populations are much better. Katz et al., Murphy et al., Yoo et al., and Michelaskos et al. reported that borderline-resectable pancreatic cancer patients who underwent treatment with FOLFIRI$\mathrm{NOX} \pm$ chemoradiotherapy achieved an $\mathrm{R} 0$ resection rate of $50 \%-68.0 \%$ [14, 25-27]. Yoo et al. [27] and Michelakos et al. [25] also found that patients who underwent surgical resection had significantly better progression-free survival and overall survival than nonoperated patients. The reported median survival was between 37.7 months and not reached.

The study treatments resulted in a fundamental change in tumor resectability assessments, with an increased rate of "R0 resection possible." However, the panel surgeons found that 9/24 treatment-completers still were not R0-resectable, which surgery later proved to be incorrect. This attests to the difficulty of making a correct preoperative assessment of tumor resectability after neoadjuvant treatment, as confirmed by Ferrone et al. [28] and Wagner et al. [29]. Although both groups reported that neoadjuvant treatment FOLFIRINOX \pm chemoradiotherapy led to a significant decrease in tumor size, CT did not predict the resectability (R0 resection). However, our data suggest that patients with complete resection (R0) benefit from surgery. Due to the low number of patients with $\mathrm{R} 1 / \mathrm{R} 2$ resection, no conclusion could be drawn concerning whether there is any benefit of surgery for these patients; here perhaps we need to wait for the results of the final analysis.

The observed postoperative mortality rate of $5.5 \%$ in our study was comparable to that of $6.5 \%-11.5 \%$ estimated by Krautz et al., Nimptsch et al., and Zimmermann et al. for German inpatients after major pancreatic cancer surgery [30-32]. Czosnyka et al. did not observe increased postoperative toxicity after neoadjuvant treatment with chemotherapy alone, radiation alone, or combined chemotherapy/radiotherapy before pancreatectomy in 3408 patients [33]. Golcher et al. and Dindo et al., in a randomized study of patients with resectable pancreatic cancer, found no increased toxicity after neoadjuvant chemoradiotherapy [34, 35].

\section{Conclusions}

Our data show that even if pancreatic cancer is staged as unresectable at primary diagnosis, tumor resectability should be reassessed after neoadjuvant treatment. If healthy enough, patients with a good probability of R0 resection should undergo surgery, as this significantly improves their 
prognosis. Therefore, surgery is an option that should be included in the treatment concept for these patients. However, current methods (CT and MRI) for assessing the resectability of pancreatic cancer do not always reliably predict R0 resectability. Therefore, it is necessary to search for new ways to improve $\mathrm{R} 0$ resectability assessments.

Acknowledgements We thank our study coordinators A. Kergaßner, S. Rutzner, A. Klock, K. Zierau, A. Schuricht, M. Reiss, A. Bartels, A. Nateghian, S. Neumann, V. Brunzel, T. Auchter, and J. Kreutzer for excellent patient support.

We thank the following study center for enrollment of $<6$ patients into the trial:

U.M. Martens (Department of Hematology/Oncology, Cancer Center Heilbronn-Franken, SLK-Kliniken Heilbronn, Heilbronn, Germany); B. Opitz (Hospital St. Elisabeth/St. Barbara Halle, Halle [Saale], Germany); T. Kubin (Department of Hematooncology, Klinikum Traunstein, Traunstein, Germany); M. Sinn (Universitätsmedizin Charité Berlin, CONKO Study Group, Department of Medical Oncology, Haematology and Tumorimmunology, Berlin, Germany); M. Federlein (Department of General and Visceral Surgery, Affiliated Teaching Hospital to the Charité, Sana Hospital Lichtenberg, Sana Hospitals Berlin-Brandenburg, Germany); R. Mantke (Brandenburg Medical School, Department of Surgery, University Hospital Brandenburg/ Havel, Brandenburg, Germany); G.G. Grabenbauer (Coburg Cancer Center, Coburg Hospital, Coburg, Germany); M. Geiger (Klinik für Radiotherapie, Onkologie, Diagnostische Radiologie und Nuklearmedizin, Ostfildern, Germany); G. Illerhaus (Department of Hematology and Oncology and Palliative Care, Klinikum Stuttgart, Germany); D.M. Behringer (Department of Hematology, Oncology and Palliative Care, Augusta Hospital, Bochum, Germany); H. Lambertz (Department of Oncology, Klinikum Garmisch-Partenkirchen, GarmischPartenkirchen, Germany); H. Schmidberger (Department of Radiation Oncology, University Medical Center of the Johannes Gutenberg University, Mainz, Germany); P. Michl (Klinik für Gastroenterologie und Endokrinologie, Universitätsklinikum Gießen und Marburg, Marburg); N. Moosmann (Department of Surgery, Barmherzige Brüder Krankenhaus Regensburg, Regensburg, Germany); F. Lordick (University Cancer Center Leipzig (UCCL), University Hospital of Leipzig, Leipzig, Germany); F. Griesinger (Department of Hematology and Oncology, Pius Hospital Oldenburg, Oldenburg, Germany); M. Bertram (Hämatolotisch-Onkologische Schwerpunktpraxis, Hamburg, Germany); N. Härtel (Department of Medicine II, Universitätsmedizin Mannheim, Medical Faculty Mannheim, University Heidelberg, Mannheim, Germany); M. Bitzer (Department of Gastroenterology, Hepatology, Infectious Diseases, Medical University Hospital, Tübingen, Germany); F. Lammert (Department of Medicine II, Saarland University Medical Center, Homburg, Germany); K. Ridwelski (Department of Surgery, Hospital Magdeburg, Magdeburg, Germany); H.T. Eich (Department of Radiation Oncology, University of Münster, Münster, Germany); C. Denzlinger (Marienhospital Stuttgart, Stuttgart, Germany); H. Kirchen (Department of Internal Medicine I, Krankenhaus der Barmherzigen Brüder Trier, Trier, Germany); V. Kunzmann (Section of Clinical Oncology, Department of Internal Medicine II, University Hospital Wuerzburg, Bavaria, Germany); W. Schmiegel (Department of Gastroenterology and Hepatology, University Hospital Bochum, Bochum, Germany); L. Müller (Oncology Outpatient Centre Unter-Ems, Leer, Germany); T. Seufferlein (Department of Internal Medicine I, University Hospital Ulm, Ulm, Germany).

Funding The work was funded by the German Cancer Aid (Deutsche Krebshilfe 109284).
Author Contribution Conceptualization: R. Fietkau, U.A. Wittel, H. Oettle, and W.M. Hohenberger; methodology: all authors; software: R. Fietkau, H. Oettle; validation: all authors; formal analysis: all authors; investigation: all authors; resources: R. Fietkau, H. Oettle; data curation: all authors; writing — original draft preparation: all authors; writing-review and editing: all authors; visualization: R. Fietkau, H. Oettle; supervision: all authors; project administration: R. Fietkau, H. Oettle; funding acquisition: R. Fietkau. All authors have read and agreed to the published version of the manuscript.

Funding Open Access funding provided by Projekt DEAL.

Conflict of interest R. Fietkau, R. Grützmann, U.A. Wittel, R.S. Croner, L. Jacobasch, U.P. Neumann, A. Reinacher-Schick, D. Imhoff, S. Boeck, L. Keilholz, H. Oettle, W.M. Hohenberger, H. Golcher, W.O. Bechstein, W. Uhl, A. Pirkl, W. Adler, S. Semrau, S. Rutzner, M. Ghadimi, and D. Lubgan declare that they have no competing interests.

Open Access This article is licensed under a Creative Commons Attribution 4.0 International License, which permits use, sharing, adaptation, distribution and reproduction in any medium or format, as long as you give appropriate credit to the original author(s) and the source, provide a link to the Creative Commons licence, and indicate if changes were made. The images or other third party material in this article are included in the article's Creative Commons licence, unless indicated otherwise in a credit line to the material. If material is not included in the article's Creative Commons licence and your intended use is not permitted by statutory regulation or exceeds the permitted use, you will need to obtain permission directly from the copyright holder. To view a copy of this licence, visit http://creativecommons.org/licenses/by/4. $0 /$.

\section{References}

1. Siegel RL, Miller KD, Jema A (2015) Cancer statistics, 2015. CA Cancer J Clin 65(1):5-29. https://doi.org/10.3322/caac.21254

2. Lutz MP, Zalcberg JR, Ducreux M, Aust D, Bruno MJ, Buchler MW, Delpero JR, Gloor B, Glynne-Jones R, Hartwig W et al (2017) 3rd St. Gallen EORTC Gastrointestinal Cancer Conference: Consensus recommendations on controversial issues in the primary treatment of pancreatic cancer. Eur J Cancer 79:41-49. https://doi. org/10.1016/j.ejca.2017.03.022

3. Tempero MA, Malafa MP, Al-Hawary M, Asbun H, Bain A, Behrman SW, Benson AB 3rd, Binder E, Cardin DB, Cha $\mathrm{C}$ et al (2017) Pancreatic adenocarcinoma, version 2.2017, NCCN clinical practice guidelines in oncology. J Natl Compr Canc Netw 15(8):1028-1061. https://doi.org/10.6004/jnccn.2017.0131

4. Bhayani NH, Enomoto LM, James BC, Ortenzi G, Kaifi JT, Kimchi ET, Staveley-O'Carroll KF, Gusani NJ (2014) Multivisceral and extended resections during pancreatoduodenectomy increase morbidity and mortality. Surgery 155(3):567-574. https://doi.org/10. 1016/j.surg.2013.12.020

5. Petrucciani N, Debs T, Nigri G, Giannini G, Sborlini E, Kassir R, Ben Amor I, Iannelli A, Valabrega S, D'Angelo F et al (2018) Pancreatectomy combined with multivisceral resection for pancreatic malignancies: is it justified? Results of a systematic review. HPB (Oxford) 20(1):3-10. https://doi.org/10.1016/j.hpb.2017.08.002

6. Bachmayer S, Fastner G, Vaszi A, Iglseder W, Kopp P, Holzinger J, Dinnewitzer A, Rinnerthaler G, Gampenrieder SP, Emmanuel K et al (2018) Nonmetastatic pancreatic cancer: improved survival with chemoradiotherapy $>40$ Gy after systemic treatment. Strahlenther Onkol 194(7):627-637. https://doi.org/10.1007/s00066-0181281-7

7. Satoi S, Yamaue H, Kato K, Takahashi S, Hirono S, Takeda S, Eguchi H, Sho M, Wada K, Shinchi H et al (2013) Role of adjuvant 
surgery for patients with initially unresectable pancreatic cancer with a long-term favorable response to non-surgical anti-cancer treatments: results of a project study for pancreatic surgery by the Japanese Society of Hepato-Biliary-Pancreatic Surgery. J Hepatobiliary Pancreat Sci 20(6):590-600. https://doi.org/10.1007/ s00534-013-0616-0

8. Dobiasch S, Goerig NL, Fietkau R, Combs SE (2018) Essential role of radiation therapy for the treatment of pancreatic cancer: novel study concepts and established treatment recommendations. Strahlenther Onkol 194(3):185-195. https://doi.org/10.1007/ s00066-017-1227-5

9. Mazzola R, Fersino S, Aiello D, Gregucci F, Tebano U, Corradini S, Di Paola G, Cirillo M, Tondulli L, Ruffo G et al (2018) Linacbased stereotactic body radiation therapy for unresectable locally advanced pancreatic cancer: risk-adapted dose prescription and image-guided delivery. Strahlenther Onkol 194(9):835-842. https:// doi.org/10.1007/s00066-018-1306-2

10. Matuschek C, Haussmann J, Bolke E, Tamaskovics B, Djiepmo Njanang FJ, Orth K, Peiper M, Gerber PA, Anooshar B, Kammers $\mathrm{K}$ et al (2019) Adjuvant radiochemotherapy vs. chemotherapy alone in gastric cancer: a meta-analysis. Strahlenther Onkol 195(8):695-706. https://doi.org/10.1007/s00066-019-01431-y

11. Vitz S, Gobel H, Leibl B, Aigner T, Grabenbauer GG (2018) Adenocarcinoma of the oesophagus: neoadjuvant chemoradiation and radical surgery: long-term results. Strahlenther Onkol 194(11):1007-1016. https://doi.org/10.1007/s00066-018-1320-4

12. Conroy T, Desseigne F, Ychou M, Bouche O, Guimbaud R, Becouarn Y, Adenis A, Raoul JL, Gourgou-Bourgade S, de la Fouchardiere $\mathrm{C}$ et al (2011) FOLFIRINOX versus gemcitabine for metastatic pancreatic cancer. N Engl J Med 364(19):1817-1825. https://doi.org/10.1056/NEJMoa1011923

13. Team RC (2017) R: A language and environment for statistical computing. R Foundation for Statistical Computing, Vienna

14. Katz MHG, Shi Q, Ahmad SA, Herman JM, Marsh RD, Collisson E, Schwartz L, Frankel W, Martin R, Conway W et al (2016) Preoperative modified FOLFIRINOX treatment followed by capecitabine-based chemoradiation for borderline resectable pancreatic cancer alliance for clinical trials in oncology trial A021101. JAMA Surg. https://doi.org/10.1001/jamasurg.2016.1137

15. Bouchart C, Navez J, Closset J, Hendlisz A, Van Gestel D, Moretti L, Van Laethem JL (2020) Novel strategies using modern radiotherapy to improve pancreatic cancer outcomes: toward a new standard? Ther Adv Med Oncol 12:1758835920936093. https://doi.org/10.1177/1758835920936093

16. Gemenetzis G, Groot VP, Blair AB, Laheru DA, Zheng L, Narang AK, Fishman EK, Hruban RH, Yu J, Burkhart RA et al (2019) Survival in locally advanced pancreatic cancer after neoadjuvant therapy and surgical resection. Ann Surg 270(2):340-347. https://doi.org/ 10.1097/SLA.0000000000002753

17. Hosein PJ, Macintyre J, Kawamura C, Maldonado JC, Ernani V, Loaiza-Bonilla A, Narayanan G, Ribeiro A, Portelance L, Merchan JR et al (2012) A retrospective study of neoadjuvant FOLFIRINOX in unresectable or borderline-resectable locally advanced pancreatic adenocarcinoma. BMC Cancer 12:199. https://doi.org/10. 1186/1471-2407-12-199

18. Marthey L, Sa-Cunha A, Blanc JF, Gauthier M, Cueff A, Francois E, Trouilloud I, Malka D, Bachet JB, Coriat R et al (2015) FOLFIRINOX for locally advanced pancreatic adenocarcinoma: results of an AGEO multicenter prospective observational cohort. Ann Surg Oncol 22(1):295-301. https://doi.org/10.1245/s10434014-3898-9

19. Nanda RH, El-Rayes B, Maithel SK, Landry J (2015) Neoadjuvant modified FOLFIRINOX and chemoradiation therapy for locally advanced pancreatic cancer improves resectability. J Surg Oncol 111(8):1028-1034. https://doi.org/10.1002/jso.23921
20. Nitsche U, Wenzel P, Siveke JT, Braren R, Holzapfel K, Schlitter AM, Stoss C, Kong B, Esposito I, Erkan M et al (2015) Resectability after first-line FOLFIRINOX in initially unresectable locally advanced pancreatic cancer: a single-center experience. Ann Surg Oncol 22:S1212-S1220. https://doi.org/10.1245/s10434-0154851-2

21. Sadot E, Doussot A, O'Reilly EM, Lowery MA, Goodman KA, Do RKG, Tang LH, Gonen M, D'Angelica MI, DeMatteo RP et al (2015) FOLFIRINOX induction therapy for stage 3 pancreatic adenocarcinoma. Ann Surg Oncol 22(11):3512-3521. https://doi.org/ 10.1245/s10434-015-4647-4

22. Suker M, Beumer BR, Sadot E, Marthey L, Faris JE, Mellon EA, El-Rayes BF, Wang-Gillam A, Lacy J, Hosein PJ et al (2016) FOLFIRINOX for locally advanced pancreatic cancer: a systematic review and patient-level meta-analysis. Lancet Oncol 17(6):801810. https://doi.org/10.1016/S1470-2045(16)00172-8

23. Neoptolemos JP, Palmer DH, Ghaneh P, Psarelli EE, Valle JW, Halloran CM, Faluyi O, O'Reilly DA, Cunningham D, Wadsley J et al (2017) Comparison of adjuvant gemcitabine and capecitabine with gemcitabine monotherapy in patients with resected pancreatic cancer (ESPAC-4): a multicentre, open-label, randomised, phase 3 trial. Lancet 389(10073):1011-1024. https://doi.org/10.1016/ S0140-6736(16)32409-6

24. Sinn M, Bahra M, Liersch T, Gellert K, Messmann H, Bechstein W, Waldschmidt D, Jacobasch L, Wilhelm M, Rau BM et al (2017) CONKO-005: Adjuvant chemotherapy with gemcitabine plus erlotinib versus gemcitabine alone in patients after R0 resection of pancreatic cancer: a multicenter randomized phase III trial. J Clin Oncol 35(29):3330. https://doi.org/10.1200/Jco.2017.72.6463

25. Michelakos T, Pergolini I, Fernandez-del Castillo C, Honselmann KC, Cai L, Deshpande V, Wo JY, Ryan DP, Allen JN, Blaszkowsky LS et al (2019) Predictors of resectability and survival in patients with borderline and locally advanced pancreatic cancer who underwent neoadjuvant treatment with FOLFIRINOX. Ann Surg 269(4):733-740. https://doi.org/10.1097/Sla. 0000000000002600

26. Murphy JE, Wo JY, Ryan DP (2018) Total neoadjuvant therapy with FOLFIRINOX followed by individualized chemoradiotherapy for borderline resectable pancreatic adenocarcinoma: a phase 2 clinical trial. Oncology 4(10):1439-1439. https://doi.org/10.1001/ jamaoncol.2018.4985

27. Yoo C, Kang J, Kim KP, Lee JL, Ryoo BY, Chang HM, Lee SS, Park DH, Song TJ, Seo DW et al (2017) Efficacy and safety of neoadjuvant FOLFIRINOX for borderline resectable pancreatic adenocarcinoma: improved efficacy compared with gemcitabinebased regimen. Oncotarget 8(28):46337-46347. https://doi.org/10. 18632/oncotarget. 17940

28. Ferrone CR, Marchegiani G, Hong TS, Ryan DP, Deshpande V, McDonnell EI, Sabbatino F, Santos DD, Allen JN, Blaszkowsky LS et al (2015) Radiological and surgical implications of neoadjuvant treatment with FOLFIRINOX for locally advanced and borderline resectable pancreatic cancer. Ann Surg 261(1):12-17. https://doi. org/10.1097/Sla.0000000000000867

29. Wagner M, Antunes C, Pietrasz D, Cassinotto C, Zappa M, Cunha AS, Lucidarme O, Bachet JB (2017) CT evaluation after neoadjuvant FOLFIRINOX chemotherapy for borderline and locally advanced pancreatic adenocarcinoma. Eur Radiol 27(7):3104-3116. https://doi.org/10.1007/s00330-016-4632-8

30. Krautz C, Nimptsch U, Weber GF, Mansky T, Grutzmann R (2018) Effect of hospital volume on in-hospital morbidity and mortality following pancreatic surgery in Germany. Ann Surg 267(3):411-417. https://doi.org/10.1097/Sla.0000000000002248

31. Nimptsch U, Krautz C, Weber GF, Mansky T, Grutzmann R (2016) Nationwide in-hospital mortality following pancreatic surgery in 
Germany is higher than anticipated. Ann Surg 264(6):1082-1090. https://doi.org/10.1097/SLA.0000000000001693

32. Zimmermann C, Distler M, Jentsch C, Blum S, Folprecht G, Zophel K, Polster H, Troost EGC, Abolmaali N, Weitz J et al (2020) Evaluation of response using FDG-PET/CT and diffusion weighted MRI after radiochemotherapy of pancreatic cancer: a nonrandomized, monocentric phase II clinical trial-PaCa-DD-041 (Eudra-CT 2009-011968-11). Strahlenther Onkol. https://doi.org/10. 1007/s00066-020-01654-4

33. Czosnyka NM, Borgert AJ, Smith TJ (2017) Pancreatic adenocarcinoma: effects of neoadjuvant therapy on post-pancreatectomy outcomes-an American College of Surgeons National Surgical Quality Improvement Program targeted variable review. HPB (oxford) 19(10):927-932. https://doi.org/10.1016/j.hpb.2017.07.001
34. Dindo D, Demartines N, Clavien PA (2004) Classification of surgical complications: a new proposal with evaluation in a cohort of 6336 patients and results of a survey. Ann Surg 240(2):205-213. https://doi.org/10.1097/01.sla.0000133083.54934.ae

35. Golcher H, Brunner TB, Witzigmann H, Marti L, Bechstein WO, Bruns C, Jungnickel H, Schreiber S, Grabenbauer GG, Meyer T et al (2015) Neoadjuvant chemoradiation therapy with gemcitabine/ cisplatin and surgery versus immediate surgery in resectable pancreatic cancer: results of the first prospective randomized phase II trial. Strahlenther Onkol 191(1):7-16. https://doi.org/10.1007/ s00066-014-0737-7 